\title{
Article
}

\section{Superinsulation Materials for Energy-Efficient Train Envelopes}

\author{
Jannis Wernery ${ }^{1, *}$, Samuel Brunner ${ }^{1}\left(\mathbb{D}\right.$, Benedikt Weber ${ }^{2} \oplus$, Christopher Knuth ${ }^{3} \odot$ and Matthias M. Koebel $^{1}$ \\ 1 Laboratory for Building Energy Materials and Components, Empa, Swiss Federal Laboratories for Materials \\ Science and Technology, Überlandstrasse 129, CH-8600 Dübendorf, Switzerland; \\ samuel.brunner@empa.ch (S.B.); Matthias.Koebel@empa.ch (M.M.K.) \\ 2 Laboratory for Concrete \& Asphalt, Empa, Swiss Federal Laboratories for Materials Science and Technology, \\ Überlandstrasse 129, CH-8600 Dübendorf, Switzerland; benedikt.weber@empa.ch \\ 3 Laboratory for Acoustics/Noise Control, Empa, Swiss Federal Laboratories for Materials Science and \\ Technology, Überlandstrasse 129, CH-8600 Dübendorf, Switzerland; ck1g19@soton.ac.uk \\ * Correspondence: jannis.wernery@empa.ch
}

Citation: Wernery, J.; Brunner, S.; Weber, B.; Knuth, C.; Koebel, M.M. Superinsulation Materials for Energy-Efficient Train Envelopes. Appl. Sci. 2021, 11, 2939. https:// doi.org/10.3390/app11072939

Academic Editor: Eugeny Y. Kenig

Received: 17 February 2021

Accepted: 22 March 2021

Published: 25 March 2021

Publisher's Note: MDPI stays neutral with regard to jurisdictional claims in published maps and institutional affiliations.

Copyright: (c) 2021 by the authors. Licensee MDPI, Basel, Switzerland. This article is an open access article distributed under the terms and conditions of the Creative Commons Attribution (CC BY) license (https:// creativecommons.org/licenses/by/ $4.0 /)$.

\begin{abstract}
While traction energy is the main energy used in passenger trains, the energy required to condition the passenger area is significant and can account for up $40 \%$ of the total energy use. Due to space constraints, passenger train envelopes are usually only insulated with a few centimetres of conventional insulation materials, leading to relatively high U-values and high energy transmissions in climates where heating or cooling is necessary. Here, the use of superinsulation materials in trains for heating/cooling demand reduction was evaluated. Selected commercially available superinsulation materials were screened and benchmarked in terms of thermal conductivity, fire safety, behaviour under vibration and preferred use position within the train envelope. Both the specific vacuum insulation panels and silica aerogel boards that were tested were found suitable for the application in train envelopes in terms of their thermal, fire and mechanical properties. While vacuum panels have the best insulation performance, aerogel boards offer higher flexibility during installation and reduced risk of damage-related performance loss. Both materials can greatly enhance the energy efficiency and thermal comfort of trains and can be implemented cost-neutrally. However, new policy frameworks are likely to be necessary to promote energy efficiency and the broad implementation of thermal superinsulation in trains.
\end{abstract}

Keywords: railway; thermal insulation; silica aerogel; vacuum insulation panels; thermal superinsulation materials; energy efficiency; HVAC

\section{Introduction}

In transport vehicles such as trains, cars or trucks the inside temperature often needs to be kept within a certain range in order to guarantee passenger comfort or to protect temperature-sensitive goods such as food or medical supplies. Since in many countries, external temperatures deviate at least seasonally from these requirements, it is necessary to condition the inside of the vehicle and to insulate the vehicle envelope. The thermal design of the envelope determines how well the desired temperature conditions can be kept and how much energy is required to do so. In principle, this envelope design question is analogous to the considerations for the envelope of a building. In both cases, generally, the better the envelope is insulated, the easier comfort can be achieved, and the more energy-efficient the operation is. On top of the heat conduction through the envelope, energy transfer by convection through leakages-if the envelope is not air-tight enoughand by radiation through windows need to be considered for both buildings and trains. Major technical differences between the thermal design of buildings and vehicles are space constraints, different indoor temperature requirements and different requirements for mechanical strength of the structural part of the envelope. For vehicles, the latter usually results in more thermal bridges and, hence, higher U-values. 
Through both lab and field studies, the present work aims to answer the question of whether, and how, thermal superinsulation materials can be used in passenger train envelopes in order to improve the train's energy efficiency. To give context to this question, the energy use in passenger trains and the corresponding saving potential will be reviewed, followed by an overview on the thermal envelope of trains as well as insulation materials in trains. Subsequently, a description of thermal superinsulation materials and their applications in buildings as well as examples of superinsulation materials in transport will be given.

Traction energy, i.e., the energy needed to move the train, is the main energy use in passenger trains. Traction energy use and its optimisation have been studied thoroughly. For example, Chang and co-workers [1] modelled the overall energy and greenhouse gas impact of high-speed trains (including manufacturing and infrastructure) and found values between 54 and $178 \mathrm{~g}$ of $\mathrm{CO}_{2}$-equivalent per passenger kilometre travelled, which is significantly lower than for air or car travel. The actual traction energy can oftentimes be optimised further. Huang et al. [2] found that timetable optimisation can lead to reduced travel times in urban trains and a total energy use reduction of up to $27 \%$, whereas Zhang and co-authors [3] found an almost $8 \%$ improvement potential in timetable optimisation for a high-speed train. Additionally, maximum urban train speeds can be optimised for energy use as demonstrated by a study of Feng and colleagues [4].

While traction energy use is the largest part of the total energy needed to operate the train, the energy necessary to condition the train's interior, i.e., the energy need for heating, ventilation and cooling (HVAC), can be significant, accounting for up to $30-40 \%$ of the total energy use [5,6]. Hence, the optimisation of HVAC energy use is an evident next step after considering traction energy in order to make railway transport even more sustainable. Hofstadter and co-workers [7] used a model predictive control-based framework to optimise HVAC operation in trams, which was implemented in a tram in Vienna, calculating an estimated annual energy saving of $32 \%$. By modelling the conditioning of a Swiss train of Rhätische Bahn with the software IDA ICE, Vetterli and co-workers [8] evaluated the saving potential of different improvement measures in terms of HVAC operation, train envelope and HVAC components that would keep passenger comfort unaffected. Measures with high saving potential were in order of decreasing effect: $\mathrm{CO}_{2}$-controlled (i.e., occupancybased) ventilation, reduction of the U-value of the opaque train envelope, air-tightness of the envelope, heat recovery for ventilation, reduction in U-value of the windows and heating with a heat pump. Sidler and colleagues [6] modelled different energy-saving measures for Swiss inter-city trains and found that an occupancy-based ventilation operation provided the highest savings potential with almost $42 \%$ of the total HVAC energy. Additionally, a reduction in the internal temperature down to $10{ }^{\circ} \mathrm{C}$ during standby times of the train and the heat recovery in the ventilation had strong saving effects of 22 and $27 \%$, respectively. Note that these reductions are all relative to the base scenario and, hence, not cumulative. Good saving potential for an urban train in England was found by Powell and colleagues [9] who identified that $11 \%$ of the vehicle's total energy consumption was due to on-board auxiliaries when the train was not in use (standby). Taking into account that the HVAC energy use can be up to $40 \%$ of a train's total energy consumption, this finding fits well with the analysis of Sidler and co-authors. High energy-saving potentials by implementation of an energy-saving standby mode were also reported by Oelhafen and Tonin [10] for Swiss NINA, GEX and ICN trains, especially for the winter by monitoring these trains extensively. For an Italian urban train, Barone and co-workers [5] identified the optimisation of the HVAC operation as well as the use of state-of-the-art heating and cooling systems as the largest potential energy-saving interventions, with savings potentials of up to 50 and 35\%, respectively. An improved thermal envelope only showed small possible savings. The difference between these findings and the recommendations of Vetterli et al. [8] is certainly linked to the different climates of Italy and Switzerland. Furthermore, once the HVAC operation and technology has been optimised, the thermal envelope becomes crucial for further savings. 
Additionally, other influences, such as the opening of doors, were studied. Oelhafen and Tonin [10] report that the door openings in a non-insulated trolley bus only constitute about $15 \%$ of thermal losses. The remaining losses are due to transmission through the envelope and ventilation losses. Since bus doors open much more frequently than even urban train doors, and their area constitutes a higher fraction of the total envelope, the effect of door openings in trains is likely to be much smaller.

Current insulation materials in trains, for the most part, have thermal conductivities above $30 \mathrm{~mW} /(\mathrm{m} \cdot \mathrm{K})$. These conventional insulators work by trapping air in more or less small pores. For trains, commonly used materials are glass wool, melamine resin foam, corrugated sheets of cellulose plastics, polyolefin foams (e.g., polyethylene), polyester blankets, synthetic rubber foam and expanded cork granules. A database of insulation materials used in trains in Switzerland and their material properties was created recently [11]. Björk and Enochson [12] studied the hygrothermal properties of some of these materials in more detail, namely, glass wool, melamine resin foam and corrugated sheets of cellulose plastics, for different moisture loads. The authors found that both glass wool and melamine resin took up significant amounts of moisture, reducing insulation performance. This could indicate room for improvement for the insulation of trains under moist conditions, i.e., by using materials that do not take up moisture. In a field study, Oelhafen and Tonin [10] also considered the effect of a humid insulation material—melamine resin foam-on the energy use and found it to be around 10 and $1.3 \%$ of the annual heating energy use for the FLIRT and NINA trains, respectively. Furthermore, a saving potential of roughly $20 \%$ was estimated for a NINA train with an improved thermal insulation. The actual retrofit of such a train, including the economic aspects, is described by Isenschmidt [13]. The author notes the difficulty to recuperate the cost of such a retrofit solely via the value of the energy savings and finds a payback time of 24 years, the main cost being the work to install the insulation. The situation is somewhat different for the construction of a new train, as some types of insulation must be installed anyway, thus there is no large difference whether a higher insulation thickness or a better performing material is used.

Comparing the thermal envelope of trains to those of buildings, it is interesting to note that trains operating in heating-dominated climates such as Central Europe typically have U-values between 1.5 and $2.5 \mathrm{~W} /\left(\mathrm{m}^{2} \cdot \mathrm{K}\right)[13,14]$, whereas those for modern buildings are usually in the range between 0.15 and $0.3 \mathrm{~W} /\left(\mathrm{m}^{2} \cdot \mathrm{K}\right)$ [15]. This difference exists in spite of comparable comfort requirements in buildings and passenger trains, especially for long-distance trains. However, train envelopes are under much stricter space constraints than building envelopes. This is because the outer dimensions of a train are usually limited by the track width of the railway system, by tunnels or the dimensions of train stations. Judging from discussions with train manufacturers and operators, the lower thermal performance of train envelopes compared to buildings seems to be due to four main reasons: (i) the space constraints mentioned above, (ii) structural connections in the train envelope that create a significant amount of thermal bridges, (iii) the less stringent comfort requirements in short-distance transportation (e.g., urban trains) and (iv) the considerably less stringent legal or normative requirements on maximal allowed U-values for trains. For buildings, the optimal U-value in terms of overall energy and $\mathrm{CO}_{2}$ footprint over the lifetime of the building is around 0.10 to $0.2 \mathrm{~W} /\left(\mathrm{m}^{2} \cdot \mathrm{K}\right)$, depending on the insulation material and heating system [16]. For such a building, increasing the insulation thickness can result in an increase in embodied energy, which is not offset by the energy savings during operation in the building's whole lifetime anymore-especially when low $\mathrm{CO}_{2}$ heat sources are used, as is more and more common nowadays, such as heat pumps driven by low $\mathrm{CO}_{2}$ electricity. Hence, the U-values of modern buildings in many heating-dominated countries in Central Europe or Scandinavia are close to the energetic optimum. Train envelopes, on the other hand, are far from these elevated performance standards. Thus, an improvement of the train envelope insulation has strong potential for considerable energy savings of HVAC during train operation with only relatively small increases in 
embodied energy, reducing the overall energy consumption and ecological footprint over the train's lifetime.

Thermal superinsulation materials are characterised by a thermal conductivity of $20 \mathrm{~mW} /(\mathrm{m} \cdot \mathrm{K})$ or less and have been established in the building sector for applications with space constraints in the last 20 years. With thermal superinsulation, it is possible to achieve two to four times the thermal resistance compared to conventional insulation materials at the same insulation thickness. Alternatively, very thin building envelopes can be built that still insulate just as well as conventional, thick envelopes. Superinsulation materials are used for inner-city buildings where space is at a premium and for the retrofit of existing buildings, especially for historic ones [17]. Additionally, architectural details such as window reveals, roller shutter housings or dormer window walls are common applications [18]. However, superinsulation materials are usually significantly more expensive than conventional insulation materials for the same level of performance.

With the space constraints in trains, superinsulation materials are ideal to achieve a superior thermal performance in the thermal envelope of trains. Despite this potential advantage, there is very little documentation on their use in trains and in transport in general, especially in the scientific literature. Asian manufacturers of aerogel advertise the properties of their materials as ideal for use in train insulation but do not document any applications in train envelopes $[19,20]$. Vacuum insulation panels (VIPs) have been evaluated by simulation for the use in refrigerated vehicles by Gaedke and colleagues [21] who found that the cooling energy used could be halved by using VIPs instead of rigid polyurethane boards. Kraus and co-authors [22] studied the puncture resistance of VIPs with different post-reinforcement methods in order to improve their durability in transport applications under high dynamic load. They reported that the necessary penetration energy can be doubled by pouring hotmelt on the panels. A German vacuum panel manufacturer studied the effect of including VIPs in the envelope of an electric car, the BMW i3, on thermal comfort and range of the vehicle. They found that significantly higher inside temperatures were possible in the winter scenario and significantly lower ones in the summer scenario. Furthermore, the range of the car at a very low temperature of $-15^{\circ} \mathrm{C}$ was increased by ca. $40 \%$ [23]. Additionally, the application of VIPs in a commercial van for refrigerated transport was advertised recently [24].

However, there are several open questions regarding the use of superinsulation materials in trains, which may have hindered their application in trains so far. For example, all materials used in trains have to satisfy specific requirements regarding fire behaviour, depending on the type of train and route. These are different from the material classifications of EN 13501-1 for buildings [25], according to which most superinsulation materials have been characterised. Furthermore, the insulation materials in trains are subject to vibrations, which could compromise their mechanical integrity. Hence, it is not clear if the superinsulation materials that have been used successfully as building insulation are ultimately also suitable to insulate trains.

In order to close this knowledge gap, the application of superinsulation materials as train insulation was evaluated, considering thermal properties, fire properties, mechanical properties as well as workability for installation in trains. The goal of this study is to provide the necessary data and knowledge to train manufacturers and policymakers that is needed in order to improve energy efficiency and thermal comfort in railway and transport in general.

\section{Screening of Insulation Materials}

In order to find suitable insulation materials for the insulation of a train envelope, all commercially available superinsulation materials were identified. This was done through internet research as well as expert consultation. When there were several products of the same material type, e.g., silica aerogel boards, the product with the most suitable properties for the application in trains was selected. The superinsulation materials found in our research were vacuum insulation panels (VIPs), silica aerogel boards, polyurethane (PU) 
aerogels, fumed silica boards as well as polyisocyanurate (PIR) foams. The properties of the most suitable product in each of these material categories are listed in Table 1, and some materials are shown in Figure 1.

Table 1. Materials for screening for the application as thermal insulation in trains with selected properties.

\begin{tabular}{|c|c|c|c|c|c|c|}
\hline Product Type & Material & $\begin{array}{l}\text { Thermal } \\
\text { Conductivity in } \\
\mathrm{mW} /(\mathrm{m} \cdot \mathrm{K})^{*}\end{array}$ & $\begin{array}{l}\text { Density } \\
\left(\mathrm{kg} / \mathrm{m}^{3}\right)^{*}\end{array}$ & $\begin{array}{c}\text { Water Vapour } \\
\text { Diffusion } \\
\text { Resistance Factor } \\
\mu^{*}\end{array}$ & $\begin{array}{l}\text { Fire Rating } \\
\text { EN13501-1* }\end{array}$ & Remarks/Workability \\
\hline $\begin{array}{l}\text { Vacuum } \\
\text { insulation panel } \\
\text { (VIP), typical } \\
\text { product }\end{array}$ & $\begin{array}{l}\text { Evacuated core } \\
\text { made from } \\
\text { pyrogenic silica, } \\
\text { wrapped in a } \\
\text { metal coated } \\
\text { membrane }\end{array}$ & $7-8$ & $180-210$ & Tight/impermeable & $\mathrm{E}^{* *}$ & $\begin{array}{l}\text { Cannot be cut; has to be } \\
\text { handled carefully in } \\
\text { order to avoid damage } \\
\text { of membrane; longer } \\
\text { delivery times for } \\
\text { special sizes }\end{array}$ \\
\hline $\begin{array}{l}\text { Aerogel board, } \\
\text { typical product }\end{array}$ & $\begin{array}{c}\text { Flexible } \\
\text { hydrophobic } \\
\text { silica aerogel in } \\
\text { glass fibre matrix }\end{array}$ & 19 & 230 & 3 & A2 & $\begin{array}{l}\text { Can be handled similar } \\
\text { to mineral wool; emits } \\
\text { dust during handling }\end{array}$ \\
\hline PU aerogel board & $\begin{array}{l}\text { Rigid } \\
\text { polyurethane } \\
\text { aerogel board }\end{array}$ & 18 & $110-135$ & 8 & $\mathrm{E}$ & $\begin{array}{c}\text { Easy to cut and handle; } \\
\text { introduction to market } \\
\text { expected in the next } \\
\text { years }\end{array}$ \\
\hline $\begin{array}{l}\text { PIR board, high } \\
\text { performance }\end{array}$ & $\begin{array}{l}\text { Polyisocyanurate } \\
\text { foam board }\end{array}$ & 18 & $\sim 30$ & Tight/impermeable & E & Easy to cut and handle \\
\hline $\begin{array}{c}\text { Fumed silica } \\
\text { board }\end{array}$ & $\begin{array}{l}\text { Fumed silica } \\
\text { compacted into } \\
\text { rigid board }\end{array}$ & 20 & 165 & 5 & $\mathrm{~A} 2$ & $\begin{array}{l}\text { Has to be handled } \\
\text { carefully; low } \\
\text { mechanical stability }\end{array}$ \\
\hline
\end{tabular}

* according to manufacturer, for VIP thermal conductivity including aging, edge effects and joints ** for VIPs without an additional fire protection layer as commonly sold by producers; with an additional fire protection layer, better results can be achieved.

Vacuum insulation panels consist of an open pore core material, most commonly fumed silica or glass wool, and a metallised, air- and vapour-tight envelope that is evacuated during production. The thermal conductivity of VIPs right after production can be as low as $2-4 \mathrm{~mW} /(\mathrm{m} \cdot \mathrm{K})$ at the centre of the panel. Taking into account their "aging", i.e., the decreasing of the vacuum quality over time, as well as thermal bridging via the panel edge, official declaration values for VIPs with pyrogenic silica core in Europa are typically $7 \mathrm{~mW} /(\mathrm{m} \cdot \mathrm{K})$. This value is a mean value over the panel's assumed lifetime of over 25 years and likely up to 50 years, which should not be exceeded within the first 12 years [26]. Vacuum panels are vapour tight and come in fixed sizes. They are the superinsulation materials with the highest insulation performance [27]. Silica aerogel insulators are nano-porous materials, with open pores and thermal conductivities in the range of 14 to $20 \mathrm{~mW} /(\mathrm{m} \cdot \mathrm{K})[26,28]$. Compared to VIPs, the handling of such fibre-reinforced aerogel boards is more similar to mineral wool, i.e., relatively flexible. Silica aerogel is hydrophobic; hence, its humidity uptake is minimal, making it a suitable insulation material in areas that could be exposed to high humidity. There is also a diffusion-open, rigid polyurethane aerogel board, which is not as brittle as silica aerogels [29]. In the last few years, polyisocyanurate foam insulation (PIR) boards have reached lower and lower thermal conductivities by the use of special filler gases, so that some products are in the thermal superinsulation range, with the best commercially available materials reaching thermal conductivities down to $18 \mathrm{~mW} /(\mathrm{m} \cdot \mathrm{K})$. PIR boards are diffusion-closed and can be cut and handled easily. They are significantly cheaper than both aerogels and VIPs. Finally, fumed silica powder can be pressed into board shape, reaching a thermal conductivity of $19 \mathrm{~mW} /(\mathrm{m} \cdot \mathrm{K})$ [30]. 


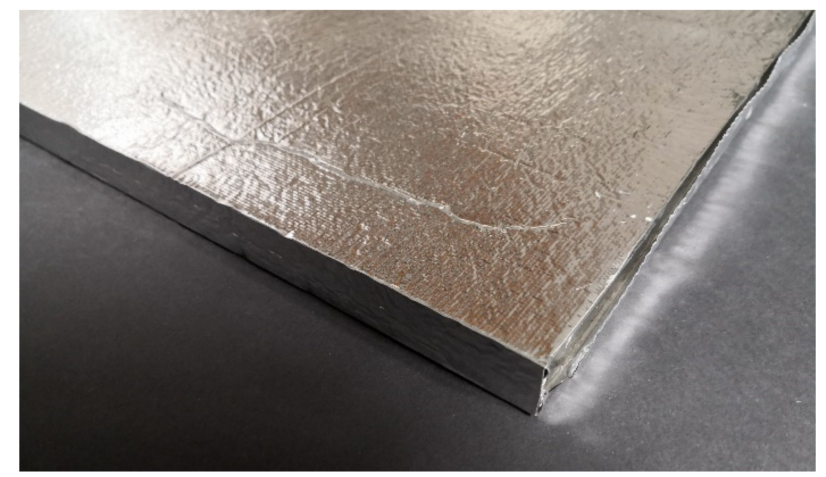

(a)

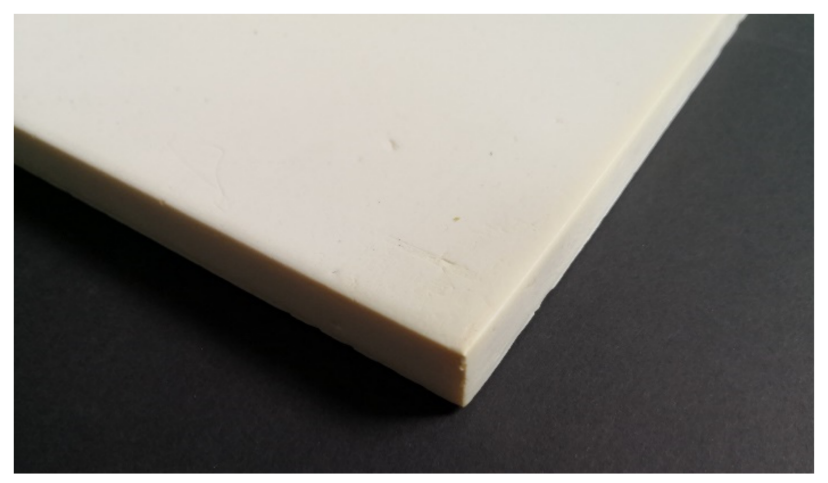

(c)

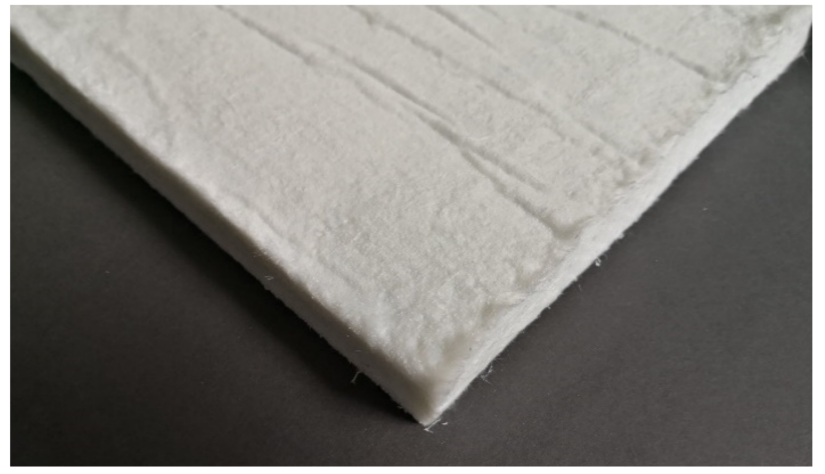

(b)

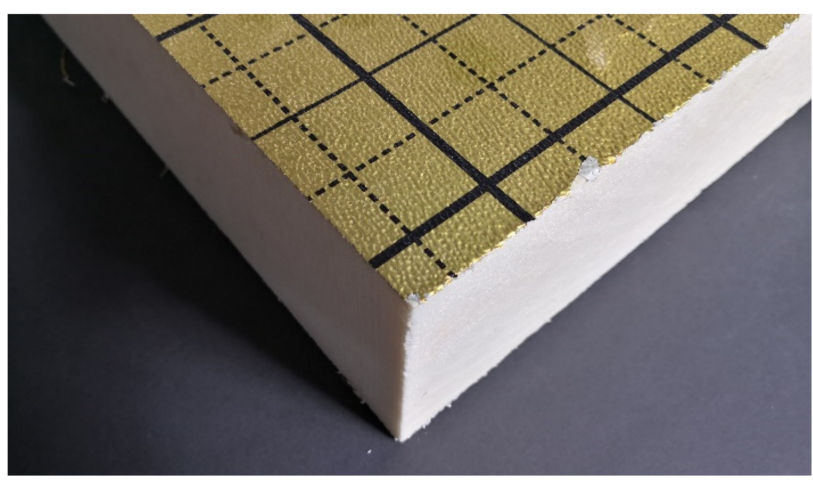

(d)

Figure 1. Thermal superinsulation materials considered for railway application: (a) vacuum insulation panel, (b) silica aerogel board, (c) polyurethane aerogel, (d) PIR board. Images: Empa.

One reservation with silica aerogels and VIPs is their significantly higher density compared to conventional insulators, cf. Table 1. This is a disadvantage, as train manufacturers try to minimise the weight of the trains in order to reduce traction energy needs.

Conventional insulation materials such as EPS, mineral wool or melamine resin foam were not considered here, as their thermal conductivities are not in the range of thermal superinsulation, more specifically, above $30 \mathrm{~mW} /(\mathrm{m} \cdot \mathrm{K})$. In order to make trains more comfortable and energy-efficient in the future, it is crucial to use space-saving insulators, i.e., thermal superinsulation.

The most important properties of the materials apart from their thermal conductivity are fire safety, mechanical stability and workability for an efficient installation.

Fire safety was an exclusion criterion in this case. The fire properties of the screened materials are classified in Table 1 according to the building material standard EN 13501-1 [25], as they are mainly used for building insulation. Materials with a high contribution to fire according to this standard-an E-classification-were not considered likely to pass the train-specific fire tests. Hence, the two polyurethane-based materials were excluded due to their fire rating. In addition to the fire contribution of the polyurethane-based materials, the extremely toxic hydrogen cyanide is created during the combustion of PIR and PU materials [31]. This would be particularly critical in the application in this work, due to the tunnel passages of the Swiss railway with decreased ventilation. The VIPs, on the other hand, were still considered but with a product that has a protective layer on the outside to increase resistance to fire. From the fire load point of view, most VIPs have a core made from a non-flammable material, and only the thin envelope is made from polymeric films with a metallisation as barrier layers. Hence, with a protective layer, fire ratings much better than E can be reached. Due to the combustion toxicity of PIR and PU aerogel boards, a similar approach was not followed for these materials. 
Materials of low mechanical stability were not considered further, because their mechanical integrity might be compromised by the constant vibrations in a moving train. The preparation and handling of the materials, e.g., cutting, drilling, etc., was also considered in order to give use recommendations for the screened materials. Here, the fumed silica board was excluded as, unlike the silica aerogel board, it has no fibre reinforcement and, hence, a lower mechanical stability (the manufacturer of the fumed silica board does not provide tensile strength data but notes that the corners and edges of the panel susceptible to damage on impact and should be transported with care [30]). Because of that, cracks or disintegration of the material under the constant vibration in a train would be likely.

Finally, vacuum insulation panels and silica aerogel boards remained as potentially suitable materials. For these, one specific product currently available on the market was examined in detail in terms of its thermal and fire properties as well as its behaviour under vibration.

\section{Methods}

\subsection{Materials}

For the thermal conductivity measurements, the VIP product Vacupor NT-B2-S of Porextherm was used (procured from manufacturer in 2018). For the measurement of fire properties and the vibration testing, the VIP product va-Q-vip of va-Q-tec was used (procured from manufacturer in 2018), since for this product, there was the option to add a fire protective layer made of mica on the face of the VIPs. VIPs with this protective layer were used in the fire tests. Both VIP types consist of a pressed core, mainly made of pyrogenic silica, and a metallised plastic envelope. The thermal conductivity is declared as $<5 \mathrm{~mW} /(\mathrm{m} \cdot \mathrm{K})$ at delivery (for such non-building application), while for building applications, the declaration value is about $7 \mathrm{~mW} /(\mathrm{m} \cdot \mathrm{K})$, taking into account edge effects at the joints of two panels. The declared density is 170 to $250 \mathrm{~kg} / \mathrm{m}^{3}$.

For all three measurements, the silica aerogel material was a HECK Aero board procured in 2016. This is a glass fibre/silica aerogel composite material, where the fibres give mechanical stability to the board. The density was declared by the manufacturer as $\leq 230 \mathrm{~kg} / \mathrm{m}^{3}$ and the thermal conductivity as $18 \mathrm{~mW} /(\mathrm{m} \cdot \mathrm{K})$. Since silica aerogel boards do not show significant aging, the fact that the sample was procured two years prior to the measurement is not expected to change the sample's thermal performance.

\subsection{Thermal Conductivity Measurements}

The thermal conductivity of the selected VIP and silica aerogel products was measured with two guarded hot plate devices in 2018.

Of the two thermal conductivity measuring devices, the larger one had a measuring zone of $300 \times 300 \mathrm{~mm}^{2}$, and a symmetrical setup, with a hot plate in the middle sandwiched by two nominally identical specimens of the tested material below and above, with sample sizes of typically $700 \times 700 \times 20$ to $700 \times 700 \times 250 \mathrm{~mm}^{3}$. This setup in turn was sandwiched by one cooling plate on top and one below. The smaller device was only able to take one sample, of the preferred size of $65 \times 65 \times 10$ to $65 \times 65 \times 15 \mathrm{~mm}^{3}$, with larger sizes being possible.

The larger device adhered to EN 12667 with $< \pm 3 \%$ and had a reproducibility of the measurement of better than $\pm 2 \%$ in general and $< \pm 5 \%$ with VIPs of $\geq 400 \times 400 \mathrm{~mm}^{2}$ [32]. The smaller device was made in the style of EN 12667 but with an absolute precision better than $\pm 10 \%$, when very different material types are compared $[33,34]$.

The VIPs were measured before and after a test period in a train of the Swiss railway operator Rhätische Bahn (RhB). For that, after the first measurement of thermal conductivity, two panels were fixed with double-sided tape on the inside of the thermal envelope of one of the technical cabinets of a control car of the train. The control car was then operative for two months before the panels were carefully removed, and their thermal conductivity was measured again. The panels were also checked for mechanical damage after this test period. 


\subsection{Measurement of Fire Properties}

The selected VIP and silica aerogel materials were evaluated according to the relevant technical standard EN 45545-2+A1:2016 for fire protection on railway vehicles [35]. For this project, a use case with high fire requirements was considered, suitable for our partner Rhätische Bahn. The fire requirements were evaluated for a standard vehicle and for operation class 4 . This operation class is for routes with tunnel sections such as the ones that Rhätische Bahn operates, with long ones such as the Vereina tunnel, which is $19 \mathrm{~km}$ in length.

Hence, the fire classification was conducted according to hazard level "HL3", the highest requirements. Depending on the application within the train, different requirements are relevant. The materials were evaluated for the application in the walls, the roof and the floor. These correspond to the requirement "R1" for walls and roof and "R10" for the floor according to EN 45545-2, respectively. Because R10 is automatically satisfied, if R1 is, only tests for the latter were performed. The tests were performed by the testing lab Lantal Textiles AG, Switzerland.

The silica aerogel board screened in this project has a fire rating of A2-s1, $\mathrm{d} 0$ according to EN 13501-1, a building-related standard. In this case, EN 45545-2+A1:2016 only requires an additional test of emission of toxic gases in order to satisfy R1 for HL3. Hence, the conventional index of toxicity was determined (CIT value). According to test T11.01 of EN ISO 5659-2:2006 [36], three samples of the silica aerogel board of size $75 \times 75 \times 29 \mathrm{~mm}^{3}$ were exposed horizontally to thermal radiation of a strength of $50 \mathrm{~kW} / \mathrm{m}^{2}$ in a test chamber without use of an ignition flame for the duration of ten minutes. The created combustion gases were analysed using FTIR to determine the CIT value. For the CIT value, the concentration of several toxic combustion gases is added up relative to reference values.

For the VIP, on the other hand, all tests according to EN 45545-2+A1:2016 were conducted. For each test, the fire protective sheet was on the test side, i.e., the side exposed in the test (either to heat or flame). The spread of flame test T02 was conducted with three samples of size $790 \times 150 \times 17 \mathrm{~mm}^{3}$ according to EN ISO 5658-2:2006 [37]. In this test, the sample is exposed to a flame on one end and the lateral spread of the flame on the sample is measured over time. The reported value is the critical heat flux at extinguishment (CFE). As the VIP material did not ignite in this test, a surface ignition test with a direct flame had to be performed additionally with three samples of sizes $250 \times 90 \times 15 \mathrm{~mm}^{3}$ according to EN ISO 11925-2:2010 [38]. The next test conducted was the cone calorimeter test T03.01 according to EN ISO 5660-1:2015 [39], where three samples of dimensions $100 \times 100 \times 17 \mathrm{~mm}^{3}$ were exposed horizontally to an irradiation of $50 \mathrm{~kW} / \mathrm{m}^{2}$ with a spark plug to aid the ignition. The heat release rate was determined from the flow rate and oxygen concentration in the combustion product stream. The relevant value is the maximum mean heat release rate, MARHE. With the tests T10.01, T10.02 and T11.01 of EN ISO 5659-2:2006, the optical density of the smoke created in the combustion of the sample was determined and the combustion gases were analysed. Three samples of dimensions $75 \times 75 \times 17 \mathrm{~mm}^{3}$ were exposed horizontally to thermal radiation of a strength of $50 \mathrm{~kW} / \mathrm{m}^{2}$ in a chamber without the use of an ignition flame for the duration of ten minutes. The developed smoke was collected and examined photometrically in a test chamber, by determination of the weakening of an incident light beam. From that, the value $\mathrm{D}_{\mathrm{s}}(4)$ was determined as the product of optical density in the test chamber after four minutes and a factor depending on the geometries of the test chamber and the sample. The $\mathrm{VOF}_{4}$ is the cumulative value of the specific optical densities after four minutes. The CIT value was determined by analysing the combustion gases with FTIR.

As VIPs cannot be cut without losing functionality, all VIP samples were manufactured specifically in the sizes required for the tests.

\subsection{Vibration Testing}

Both silica aerogel and VIPs are materials designed for industrial or building applications. Hence, there is little knowledge about their behaviour under continuous vibrations, 
as they occur in trains. The main concern was that silica aerogel boards might be compacted over time or release excessive amounts of dust and that the envelope of the VIPs would be compromised under constant vibration.

A test on the basis of the standard IEC 61373 "Railway applications-Rolling stock equipment-Shock and vibration tests" [40] was implemented. This standard distinguishes different material classes and different application points within the train. Thermal insulation is classified as Class A and Category 1 (body mounted). For long-life tests, the test specimen is subjected to a random vibration with a defined acceleration spectral density. The highest amplitude of the three directions (vertical, transverse and longitudinal) was selected with $0.532\left(\mathrm{~m} / \mathrm{s}^{2}\right)^{2} / \mathrm{Hz}$ for a mass of the material of less than $500 \mathrm{~kg}$. The limiting frequencies for this mass range were set at $\mathrm{f}_{1}=5 \mathrm{~Hz}$ und $\mathrm{f}_{2}=150 \mathrm{~Hz}$ (cf. Figure 2). According to the standard, the test duration is $15 \mathrm{~h}$. Since the goal was to determine the released dust in case of the silica aerogel material, a much longer test duration of at least $55 \mathrm{~h}$ was applied ( $58 \mathrm{~h}$ for the silica aerogel and $55 \mathrm{~h}$ for the VIP).

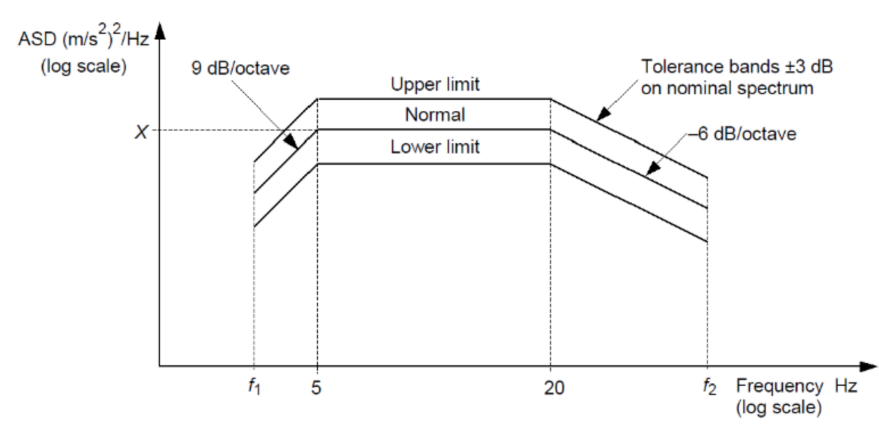

(a)

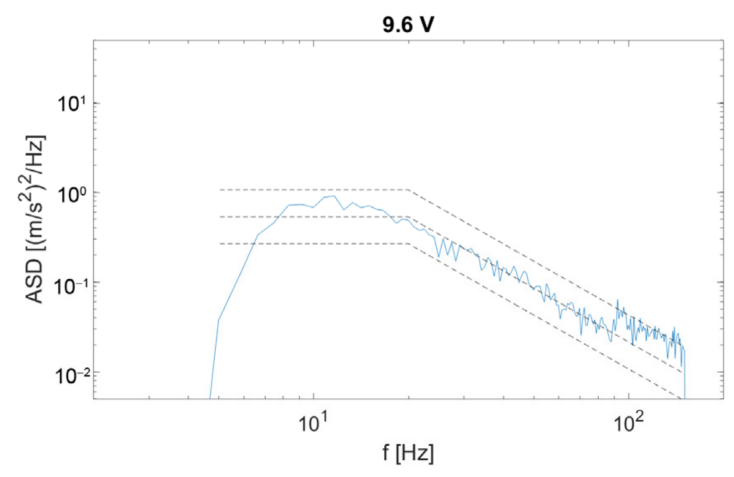

(b)

Figure 2. (a) Shape of acceleration spectral density according to IEC 61373. (b) Acceleration spectral density as measured in our setup with an RMS output voltage of the amplifier of $9.6 \mathrm{~V}$.

The vibration tests were performed using an electromagnetic shaker. A random signal with constant RMS (root mean square) between 5 and $150 \mathrm{~Hz}$ was produced by means of a signal generator and used as input to the power amplifier. The magnitude of the amplifier output was adjusted manually to obtain the desired overall vibration level of the shaker. The resulting vibration was measured with an accelerometer, and the acceleration density spectrum was determined with the MATLAB function pwelch. As shown in Figure 2, the shaker produced a spectrum within the limits of the standard IEC 61373. Note that the acceleration spectrum is modified by the dynamic characteristic of the shaker and decays with higher frequencies.

The mounting of the samples on the shaker is shown in Figure 3. The samples were glued onto an aluminium plate, which was connected to the shaker via a steel bracket. In the case of the silica aerogel board, a polyurethane-based liquid glue was used. For the VIPs, double-sided adhesive tape was employed. For the silica aerogel, the sample was furthermore covered with a bag, which was weighed before, during and after testing in order to determine the weight of the dust that was released due to the vibrations. Like that, the vibration test period for the aerogel was split into three sub-periods of roughly equal duration in order to study changes in the rate of dust release. After the testing, both aerogel and VIP samples were checked for their integrity. The sample sizes were $500 \times 500 \times 20 \mathrm{~mm}^{3}$ for the aerogel and $496 \times 496 \times 19.5 \mathrm{~mm}^{3}$ for the VIP. 


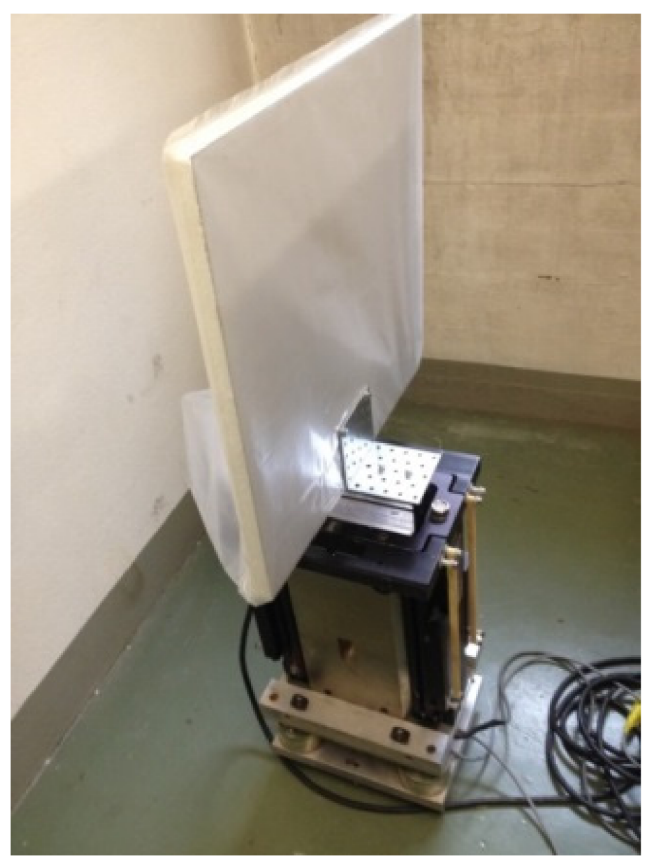

Figure 3. Vibration test setup with silica aerogel board fixed to a shaker with a plastic bag for dust collection. Image: Empa.

\subsection{Application Aspects}

For the selected VIPs and silica aerogel boards, an evaluation was made on how and where in the train envelope they should be used. For this, the handling of the materials, their thermal performance, as well as the cost of the materials was taken into account. Furthermore, the ecological aspects of the superinsulation materials were evaluated with the embodied energy and carbon dioxide.

\section{Results}

\subsection{Thermal Conductivity Measurements}

The results of the measurements of thermal conductivity are shown in Table 2. As expected, the vacuum insulation panels have the best insulation performance, in the range of 3-4 $\mathrm{mW} /(\mathrm{m} \cdot \mathrm{K})$ at the panel centre, followed by the silica aerogel board with a thermal conductivity of about $19 \mathrm{~mW} /(\mathrm{m} \cdot \mathrm{K})$. No significant change in the thermal properties was observed in the VIPs after the test period in the train. Neither was any damage visible on the panels.

Table 2. Results of the thermal conductivity measurements conducted at Empa.

\begin{tabular}{|c|c|c|c|}
\hline Material & $\begin{array}{l}\text { Thermal Conductivity } \\
(\mathrm{mW} /(\mathrm{m} \cdot \mathrm{K}))\end{array}$ & $\begin{array}{l}\text { Sample Dimensions } \\
\left(\mathrm{mm}^{3}\right)\end{array}$ & Measurement Device \\
\hline $\begin{array}{l}\text { VIP, sample } 1 \text {, before test period } \\
\text { in train }\end{array}$ & $3.5 \pm 1.0$ & $250 \times 250 \times 10$ & Small guarded hot plate, Empa \\
\hline VIP, sample 1 , after test period & $3.2 \pm 1.0$ & $250 \times 250 \times 10$ & Small guarded hot plate, Empa \\
\hline $\begin{array}{l}\text { VIP, sample } 2 \text {, before test period } \\
\text { in train }\end{array}$ & $4.0 \pm 1.0$ & $250 \times 250 \times 10$ & Small guarded hot plate, Empa \\
\hline VIP, sample 2 , after test period & $4.3 \pm 1.0$ & $250 \times 250 \times 10$ & Small guarded hot plate, Empa \\
\hline Silica aerogel board & $18.8 \pm 0.1$ & $700 \times 700 \times 21$ & $\begin{array}{l}\text { Large guarded hot plate, Empa, } \\
\text { symmetrical with } 2 \text { samples }\end{array}$ \\
\hline
\end{tabular}




\subsection{Fire Properties}

The results of the fire tests are summarised in Table 3.

Table 3. Results of the fire tests for the silica aerogel board and the VIP with a fire protection layer. Each measurement is determined with three samples. Values given represent mean values.

\begin{tabular}{|c|c|c|c|c|c|c|c|}
\hline & $\begin{array}{l}\text { MARHE } \\
\left(\mathrm{kW} / \mathrm{m}^{2}\right)\end{array}$ & $\begin{array}{c}\text { CFE } \\
\left(\mathrm{kW} / \mathrm{m}^{2}\right)\end{array}$ & $\mathrm{D}_{\mathrm{s}}(4)$ & $\mathrm{VOF}_{4}$ & $\begin{array}{l}\text { Flame } \\
\text { Spread }\end{array}$ & $\begin{array}{l}\text { Surface Ignition, } \\
\text { Flame Spread }\end{array}$ & $\mathrm{CIT}_{\mathrm{G}}$ \\
\hline $\begin{array}{l}\text { Requirement for } \\
\text { R1 HL3 }\end{array}$ & $<60$ & $<20$ & $<150$ & $<300$ & $<150 \mathrm{~mm}$ & $<150 \mathrm{~mm}$ & $<0.75$ \\
\hline $\begin{array}{l}\text { Silica aerogel } \\
\text { board }\end{array}$ & \multicolumn{6}{|c|}{ N.a. as A2 classified } & $<0.1$ \\
\hline $\begin{array}{l}\text { VIP with fire } \\
\text { protection sheet }\end{array}$ & 31.9 & 49.4 & 57.1 & 74.30 & No ignition & No ignition & 0.05 \\
\hline
\end{tabular}

For the silica aerogel boards, which already have an A2 fire rating according to EN 13501-1, the test of the emission of toxic gases yielded a mean value of the $\mathrm{CIT}_{\mathrm{G}}$ value (conventional index of toxicity) of $<0.1$ for the three measured samples. Hence, the requirements for R1 at HL3 were met for this specific product. It should be kept in mind that there are also aerogel boards that do not reach $\mathrm{A} 2$ fire ratings and for which, hence, the applicability in trains is not guaranteed.

For the VIPs, all fire tests were passed for R1 at HL3. More specifically, the cone calorimeter test yielded a mean MARHE value of $31.9 \mathrm{~kW} / \mathrm{m}^{2}$ for three samples. The spread of the flame test resulted in a mean CFE value of $49.4 \mathrm{~kW} / \mathrm{m}^{2}$ for three samples, but the samples did not ignite. The following results were found for three samples in the smoke and toxicity test with FTIR: $\mathrm{D}_{\mathrm{s}}(4)=57.1, \mathrm{VOF}_{4}=74.30$ and $\mathrm{CIT}_{\mathrm{G}}=0.05$. The surface ignition test was passed with none of the samples igniting within $60 \mathrm{~s}$.

\subsection{Vibration Testing}

After the vibration tests of $58 \mathrm{~h}$, the silica aerogel blanket had released dust, which was visible in the plastic bag around it. The mass of the total amount of dust released was determined to be ca. $0.047 \%$ of the sample weight. There was no significant change in the dust release over the measurement period. In the three sub-periods of the total duration of $58 \mathrm{~h}$, the calculated hourly dust release was $1.1,0.4$ and $1.0 \cdot 10^{-4} \% / \mathrm{h}$, respectively. Apart from the dust release, there was no visible deterioration of the sample or any delamination from the aluminium board.

For the VIP sample, no damages of the envelope or other changes were after the $55 \mathrm{~h}$ vibration period. Additionally, the fixing with double-sided adhesive tape turned out to be stable.

\subsection{Application Aspects}

Silica aerogel boards can be handled similarly to mineral wool: they can be cut, drilled and bent. These operations do release dust, however, so pre-cutting to the desired dimensions for installation in the train is preferable. VIPs, on the other hand, cannot be cut or drilled and have to be handled with care in order to prevent any damage to the envelope. They can be bent to a certain extent but less so compared to silica aerogel boards. Furthermore, for the installation location, it has to be made sure that there are no sharp edges or protrusions that could damage the envelope during the installation or the use of the train-especially given the continuous vibrations during operation. Hence, from the handling point of view, VIPs are best suited for even surfaces that are protected from mechanical stress as well as rectangular areas. While openings in VIPs for penetrations (fixation elements, etc.) or more irregular shapes can be realised during production, this increases cost, making it less attractive. Aerogel boards, on the other hand, can be handled flexibly, also allowing for higher dimensional tolerances, as they can be cut to size on site. 
From the thermal performance point of view, VIPs are superior to aerogel boards, with a thermal conductivity including aging of about half of that of aerogel boards, as shown above. This is the case, though, only for panels of sizes larger than $300 \times 400 \mathrm{~mm}^{2}$ [41] For panels of a smaller size, the thermal bridge constituted by the edge of the panel affects the performance too much, so that the use of small panels is not recommended.

Both aerogel and VIPs are significantly more expensive than conventional insulation materials, with a cost at around 5500 and 6500 EUR per $\mathrm{m}^{3}$, respectively, depending on purchase volume and manufacturer. This compares to the cost of several hundred euro per $\mathrm{m}^{3}$ for conventional materials. Considering the cost per performance, to reach, for example, a U-value of $0.2 \mathrm{~W} /\left(\mathrm{m}^{2} \cdot \mathrm{K}\right)$, the cost would be approximately 220,500 and $40 \mathrm{EUR} / \mathrm{m}^{2}$, for VIPs, silica aerogel and conventional materials, respectively. Thus, the application of these superinsulation materials is economically only justified if the desired insulation performance cannot be reached with conventional materials, i.e., due to space restrictions. As VIPs have a lower thermal conductivity than aerogel boards, their cost per insulation performance is roughly half of that of aerogel. Hence, if in a given application area, all other parameters are equal, VIPs are preferable from an economic point of view. This cost advantage is based on a sufficiently high number of items of VIPs, though, as VIPs can be produced more cost-effectively if more units are produced. Hence, for a single area of a given size that does not repeat at all, aerogel boards may still be more cost-effective.

The environmental product declarations (EPDs) of VIPs and silica aerogel boards are summarized in Table 4 with their global warming potential and the non-renewable primary energy. The values for melamine resin foam are listed for comparison. Per mass, they are in the same order of magnitude but both superinsulation materials have a much higher density, so that their performance-based footprint is significantly higher.

Table 4. Summary of environmental product declaration for Porextherm Vacupor VIP [42], Aspen Spaceloft A2 aerogel blanket [43] and melamine resin foam [44] and performance-based global warming potential and non-renewable primary energy.

\begin{tabular}{|c|c|c|c|c|c|}
\hline & $\begin{array}{l}\text { Global Warming } \\
\text { Potential } \\
\text { (kg CO} 2 \text {-eq./kg) }\end{array}$ & $\begin{array}{c}\text { Non-Renewable } \\
\text { Primary Energy } \\
(\mathrm{kWh} / \mathrm{kg})\end{array}$ & Density $\left(\mathrm{kg} / \mathrm{m}^{3}\right)$ & $\begin{array}{l}\text { Global Warming } \\
\text { Potential for } 1 \mathrm{~m}^{2} \\
\text { with } \mathrm{R}=1 \mathrm{~m}^{2} \cdot \mathrm{K} / \mathrm{W} \\
\text { (kg CO} \text {-eq.) }\end{array}$ & $\begin{array}{c}\text { Non-Renewable Primary } \\
\text { Energy for } 1 \mathrm{~m}^{2} \\
\text { with } R=1 \mathrm{~m}^{2} \cdot \mathrm{K} / \mathrm{W} \\
(\mathrm{kWh})\end{array}$ \\
\hline Vacupor & 9.24 & 43.09 & 190 & 12.3 & 57.3 \\
\hline Spaceloft, A2 & 6.25 & 33.61 & 200 & 23.8 & 127.7 \\
\hline melamine resin foam & 8.02 & 34.00 & 10 & 2.6 & 10.9 \\
\hline
\end{tabular}

\section{Discussion}

\subsection{Thermal Conductivity Measurements}

The thermal conductivity measurements confirm the good declared thermal performance of VIPs and silica aerogel boards. They are the two best commercially available thermal superinsulation materials [26]. Due to the organisation of this project, the thermal conductivity measurement was done on another product (Vacupor NT-B2-S) than the fire and vibration tests (va-Q-vip). However, the thermal conductivity of the second product is comparable to the first, with a thermal conductivity of $4.2 \mathrm{~mW} /(\mathrm{m} \cdot \mathrm{K})$ measured at Empa previously (unpublished data). For the VIPs, one should keep in mind that the vacuum degrades over time and with that their thermal conductivity increases. Hence, one should use a value of $7 \mathrm{~mW} /(\mathrm{m} \cdot \mathrm{K})$ for calculations of thermal transmittance. The fact that our results for the silica aerogel board product are slightly higher than the declaration value might be due to different measurement conditions. Here, the sample was mechanically supported at its corners, so that not the full weight of the measuring device would rest on it. This is important, since compression can lead to lower thermal conductivities for silica aerogels. We decided to measure without compression, since it corresponds better to the planned application: as a board on a wall under no compression. The results for the 
VIPs furthermore show that the thermal conductivity values of the VIP samples before and after the test installation in a train were unchanged, considering the error of the measurement. This indicates that the installation and use in a train—at least short term-do not compromise the envelope of the VIP due to vibration or other mechanical loads.

In order to better understand the implications of these results for the thermal properties of a train envelope, one can consider a simplified example of a train wall, consisting of an outside and inside metal layer sandwiching the thermal insulation, without considering any thermal bridges-which are frequent in train walls. Since the metal layers do not significantly contribute to the thermal resistance of such a wall, one can neglect them. The same holds for the external thermal surface resistance, due to the speed of a moving train. Hence, the thermal resistance, $R$, of such a wall is approximately $R=R_{\text {ins }}+R_{s i}$, with $R_{\text {ins }}=d / \lambda$ being the resistance of the insulation layer equal to the insulation layer thickness divided by its thermal conductivity and $\mathrm{R}_{\mathrm{si}}$ being the internal thermal surface resistance, which is set here to $0.13 \mathrm{~m}^{2} \cdot \mathrm{K} / \mathrm{W}$ as for buildings. The U-value of the simplified wall would be the inverse of the thermal resistance $R, U=1 / R=1 /\left(R_{s i}+d / \lambda\right)$. The values of $U$ and $R$ are shown in Table 5 for a typical insulation thickness in trains of $20 \mathrm{~mm}$ and three different thermal insulation materials: VIP, silica aerogel board and conventional thermal insulation material (e.g., melamine resin foam). This simple approximation shows the large improvement that superinsulation materials can bring for a train envelope. Of course, this is a strong simplification, as thermal bridges are very common in train envelopes due to structural reasons, and U-values of real train envelopes are significantly higher. Additionally, this U-value is not the overall U-value of the train, which, apart from thermal bridges, also takes into account the train's shape.

Table 5. Thermal resistance and U-value of a simplified train wall with different insulation for a given thickness of $20 \mathrm{~mm}$.

\begin{tabular}{cccc}
\hline & $\lambda(\mathbf{m W} /(\mathbf{m} \cdot \mathbf{K}))$ & $\mathbf{R}\left(\mathbf{m}^{2} \cdot \mathbf{K} / \mathbf{W}\right)$ & $\mathbf{U}\left(\mathbf{W} /\left(\mathbf{m}^{2} \cdot \mathbf{K}\right)\right)$ \\
\hline VIP & 7 & 2.99 & 0.33 \\
\hline Silica aerogel board & 19 & 1.18 & 0.85 \\
\hline Conventional insulation material & 32 & 0.76 & 1.32 \\
\hline
\end{tabular}

\subsection{Fire Properties}

The results of the fire tests show that the specific VIP product with the protection layer and the specific silica aerogel board selected here can both be used in train walls, roofs and floors with respect to the requirements for fire behaviour. Since the tests were conducted for the criteria of the highest hazard level "HL3", these results cover all operation classes and vehicle types defined within EN 45545-2+A1:2016, i.e., the broadest possible application within this standard on fire protection on railway vehicles. That means that the tested materials can be used, with respect to their fire behaviour, in walls, roofs and floors not only of standard vehicles but also of sleeping cars or double deck trains as covered by EN 45545-2+A1:2016.

\subsection{Vibration Testing}

The results of the vibration testing show no evidence that the vacuum panels would be compromised by the constant vibrations in trains, leading to a punctuation of the VIP envelope. This finding is supported by the results of the thermal conductivity measurements after the test period in an actual train: had there been even a small hole in the envelope, the measured thermal conductivity after the test would have been significantly higher. While the criteria in vibration tests were stricter than required in the standard IEC 61373 for railway shock and vibration tests, it cannot be excluded that vibrations over decades of a train's lifetime would lead to a breach in the VIP envelope. The results presented here, however, indicate that the risk of that happening is low and that the application should be tried. In particular, it should be considered that a ventilated VIP, i.e., no vacuum 
left, with a fumed silica core still has a thermal conductivity of about $20 \mathrm{~mW} /(\mathrm{m} \cdot \mathrm{K})$ [45], which is significantly better than any conventional insulation material currently used in trains. One could use this thermal conductivity for the calculation of the adherence to the thermal performance criteria of the train envelope in order to mitigate the risk until more experience with VIPs in trains is gathered.

The dust release observed in the aerogel boards under continuous vibration is small so that no degradation of the shape of the boards or their thermal performance is to be expected even over long time periods. Since dust in general, and hence, also aerogel dust, is harmful if inhaled, in a train application, great care needs to be taken that no dust is released from the insulation layer into the passenger area. For this reason, silica aerogel boards would not be suitable as internal insulation of a ventilation duct, for example.

\subsection{Application Aspects}

Taking into account the differences for the application of VIPs and silica aerogel boards in terms of their handling, thermal conductivity and cost per insulation performance as described in the Results section, the following recommendations can be given. If there are no space constraints, conventional materials should be used due to their lower cost and lower embodied energy and lower global warming potential. If space is constrained and a higher performance is desired, for all large, repetitive and regular areas inside the envelope of a train, VIPs are the preferred superinsulation materials due to their better performance and their cost efficiency. Given the right dimensional tolerance for the application area, VIPs can be manufactured to size and easily installed. Care should be taken during installation that the VIPs are not damaged. Quality control of the installation can be performed by subsequent thermal imaging to identify compromised VIPs in the train's envelope. For the insulation of areas that are smaller or not regular (e.g., not rectangular or of varying shape), aerogel boards should be used. These can be drilled and cut according to the needs, either by the manufacturer or on the installation site. Hence, aerogel boards can be used with much higher flexibility. Aerogel boards can also be used to "frame" VIPs if dimensional tolerance on the areas to insulate are high or if there are insulation areas of slightly varying size. For that, a VIP is installed in the middle of the area, and pieces of aerogel board are cut to size to go around it.

Since it is more costly to achieve the same thermal performance with a superinsulation material compared to a conventional one, superinsulation materials should only be used if there is an additional benefit due to the space savings achieved with them. Whether these space savings are worth the additional cost needs to be decided individually for specific applications. For example, if an additional row of seats or wider seats for more travel comfort are possible due to the space savings, the economic benefits of carrying more passengers or charging a higher ticket price can outweigh the cost premium of superinsulation materials.

One can also get an idea of the financial and environmental impact of using superinsulation materials in trains by estimating the energy savings compared to conventional insulation. As an example, a typical U-value reached with about $20 \mathrm{~mm}$ of conventional melamine resin foam insulation would be $2.0 \mathrm{~W} /\left(\mathrm{m}^{2} \cdot \mathrm{K}\right)$, taking into account thermal bridges in the train envelope (as presented in Table 5, an "unperturbed" wall without thermal bridges would have a U-value of $1.32 \mathrm{~W} /\left(\mathrm{m}^{2} \cdot \mathrm{K}\right)$ for an insulation material with a thermal conductivity of $32 \mathrm{~mW} /(\mathrm{m} \cdot \mathrm{K})$; so, the difference to the U-value of $2.0 \mathrm{~W} /\left(\mathrm{m}^{2} \cdot \mathrm{K}\right)$ is due to thermal bridges, which are more frequent in trains than buildings due to constructive reasons.). A conservative assumption for using VIPs instead of conventional insulation would be a U-value of $0.8 \mathrm{~W} /\left(\mathrm{m}^{2} \cdot \mathrm{K}\right)$ and a $\mathrm{U}$-value of $1.4 \mathrm{~W} /\left(\mathrm{m}^{2} \cdot \mathrm{K}\right)$ for using silica aerogel boards instead of conventional insulation. The difference of these U-values and the one for conventional insulation multiplied by the heating degree days for the operating region of the train is equal to the yearly energy savings. Heating degree days can be calculated by summing the difference between the target inside and mean daily outside temperatures, counting each day in a year on which the mean outside temperature falls below a defined 
base temperature. In Zurich, for example, the mean heating degree days for buildings over the time period of 2011 to 2020 are $3125^{\circ} \mathrm{d}$, with respect to the base temperature of $12{ }^{\circ} \mathrm{C}$ [46]. Since trains are not operative all day-and hence, do not need to be heated all day-a conservative value for train heating degree days is to take half of the value for buildings. Thus, one calculates an annual saving of about $45.0 \mathrm{kWh} / \mathrm{m}^{2}$ of train envelope for VIPs and of about $22.5 \mathrm{kWh} / \mathrm{m}^{2}$ for silica aerogel boards-in both cases compared to conventional melamine foam resin.

One can consider the economic payback of using superinsulation materials for the example of an ICE 4 train. A new ICE 4 train costs about 39 million EUR [47]. At a length, height and width of $375,4.1$ and $2.9 \mathrm{~m}$, respectively, it takes just under $90 \mathrm{~m}^{3}$ of insulation material to insulate such a train with $20 \mathrm{~mm}$ of insulation (subtracting $25 \%$ of window area on the side walls). Considering a thermal superinsulation cost of $4000 \mathrm{EUR} / \mathrm{m}^{3}$ and a conventional insulation material cost of $500 \mathrm{EUR} / \mathrm{m}^{3}$, the use of thermal superinsulation would incur an additional cost about $70 \mathrm{EUR} / \mathrm{m}^{2}$ of opaque train envelope and make the whole train roughly $0.8 \%$ more expensive. Assuming an electricity price of $0.1 \mathrm{EUR} / \mathrm{kWh}$ (e.g., $0.11 \mathrm{CHF} / \mathrm{kWh}$ for Swiss trains [48]) and not considering any transforming losses when using this electricity for heating, the thermal superinsulation would only be paid back in about 16 years for VIP and in about 31 years for silica aerogel boards. Since no energy savings for cooling due to the better U-values were considered here, the actual payback time would be somewhat shorter. The same holds if electricity prices would become higher. On the other hand, discounting and opportunity costs for such an investment into a more expensive insulation are not considered, which would increase the payback period. This very rough estimation indicates that using thermal superinsulation in trains may be financially interesting or not depending on the specific train and climate at hand. Thus, the individual situation needs to be considered and evaluated in detail in order to answer the question of financial feasibility of thermal superinsulation in that case.

The same approach can be used to estimate the ecological payback of superinsulation materials in trains, at least in terms of embodied energy. Considering the density and embodied energy of VIPs, silica aerogel boards and melamine resin foam according to Table 4, one can calculate the difference in embodied energy per square metre of $20 \mathrm{~mm}$ insulation between the superinsulation materials and the conventional melamine resin foam. This difference would be $156.9 \mathrm{kWh} / \mathrm{m}^{2}$ for the VIPs and $127.6 \mathrm{kWh} / \mathrm{m}^{2}$ for the silica aerogel boards. Dividing by the yearly energy savings of 45.0 and $22.5 \mathrm{kWh} / \mathrm{m}^{2}$ for VIPs and aerogel, respectively, the result is an embodied energy payback period of about 3.5 and 5.7 years for VIPs and silica aerogel boards, respectively. This is much shorter than the operation duration of trains of about 30 years or more. Hence, this rough estimation of embodied energy payback shows that the use of superinsulation materials to achieve lower U-values in trains is clearly indicated from an ecological point of view. This holds in spite of the fact that many train operators in Europe use already renewable energy, since overall, Europe is still far from a completely renewable electricity production with $34 \%$ renewable electricity for 2019 [49]. Therefore, any energy saved in the transport sector-be it renewable or not-can be used in other sectors where the energy mix is not completely green yet.

\section{Conclusions and Outlook}

The present study on thermal, fire and mechanical properties of superinsulation materials as well as their application aspects shows the large potential of these materials for the improvement of energy efficiency and thermal comfort in trains.

To our knowledge, this is the first publication that demonstrates the feasibility of using VIPs and silica aerogels in trains so that the studied products can now be applied with good confidence. A clear conclusion that can be draw here is that these materials should in fact be applied in order to increase energy efficiency and thermal comfort. It should be noted that these statements are valid for the specific discussed products, and not all aerogel nor VIP products fulfil the requirements for trains. 
A rough analysis of the economics of train insulation for new trains indicates that substituting VIPs or silica aerogel boards for conventional insulation materials at the same thickness is cost-neutral or cost-saving over the life-time of the train due to the energy savings these materials allow. Additionally, surface temperatures on the inside of the train envelope will be higher, which improves thermal comfort and might allow for lower air temperatures, while still achieving good thermal comfort, leading to further energy savings. Since the increase in embodied energy due to the use of VIPs or silica aerogel boards is compensated by energy savings during the train's operation within a few years, these superinsulation materials should be used instead of conventional materials whenever possible. Of course it is possible to insulate "too much", i.e., when the embodied energy of adding more insulation is not compensated by additional energy savings any further. However, this would happen at much lower U-values-in the building context at around 0.1 to $0.2 \mathrm{~W} /\left(\mathrm{m}^{2} \cdot \mathrm{K}\right)[16]$.

In order to mitigate the limitations in the handling of superinsulation materials, especially of VIPs, their use should be considered already in the early phases of train design, so that solutions can be found that are compatible with the use of these materials. Other applications, such as refrigerators where VIPs are commonly used, show that it is possible to accommodate for the specialty of this material by design considerations.

The clear recommendation of this study to use suitable superinsulation materials in space constraint thermal envelopes can be extended to other types of public transport such as buses and trams, at least in terms of thermal and mechanical properties as well as the application aspects. The fire behaviour requirements for these other transports might be different than for railway and need to be taken into account separately.

As next steps building on these results, one should evaluate superinsulation material solutions in more detail through field studies over long time periods with the monitoring of hygrothermal and mechanical properties. This will further reduce the unknowns and the risks associated with the use of these new materials in railway applications. Additionally, the thermal properties of a whole train should be studied, comparing both conventional and superinsulation materials. This could be done initially with simulations and, subsequently, with measurements on train prototypes. In such an analysis, a more detailed evaluation should be performed of the economic feasibility of using thermal superinsulation as well as of the optimal insulation thickness considering the maximally available space, energy savings, additional cost of the material compared to conventional insulators, increase in embodied energy of the insulation as well as any traction energy increases due to higher weight.

These types of studies could greatly support the introduction of stricter energy efficiency labels or legal performance requirements for trains by demonstrating what is possible with state-of-the-art insulation materials. We believe that changes towards more energy-efficient trains with lower U-values and optimised HVAC systems will likely be driven mostly by stricter requirements for the thermal envelopes of trains. This is because neither train manufacturers nor railway operators have strong incentives to increase energy efficiency. There has been somewhat of a shift, for example, with the introduction of full-cost energy billing for operators [50], so that energy efficiency slowly becomes a relevant optimisation factor besides cost, comfort requirements and maximum passenger space. The introduction of a maximum allowed U-value or of a cap of the total energy use for a given train would likely accelerate this shift towards energy efficiency in railway-in a similar way as legal requirements and labels have done in the building sector.

Author Contributions: Conceptualization, J.W., S.B. and M.M.K.; funding acquisition, J.W. and M.M.K.; investigation, J.W., S.B., B.W. and C.K.; methodology, J.W. and S.B.; project administration, J.W.; supervision, J.W.; writing—original draft, J.W.; writing—review and editing, J.W., S.B., B.W., C.K. and M.M.K. All authors have read and agreed to the published version of the manuscript.

Funding: This work was financially supported by the Swiss Federal Office of Transport, Bern, Switzerland, with the BAV project No. 79. We are grateful for this support. 
Institutional Review Board Statement: Not applicable.

Informed Consent Statement: Not applicable.

Data Availability Statement: The data presented in this study is available in this article.

Acknowledgments: We would like to thank Rhätische Bahn, in particular Magnus Kowol, for making the tests within one of their trains possible, and Urs Pachale and Stefan Schoenwald for their support with the vibrational tests. We thank our partners in this project from BFH, EPFL, HSLU, Rhätische Bahn and Stadler Altenrhein AG, BAV as well as Empa for the productive collaboration and the fruitful discussions: Roman Hausammann, Wolfgang Rädle, Urs Uehlinger, Christoph Geyer, Karim Ghazi Wakili, Andreas Schüler, Jérémy Fleury, Franz Sidler, Urs-Peter Menti, Gerhard Zweifel, Magnus Kowol, Martin Stamm, Stefan Schnell and Lukas Huber. We would also like to thank Peter Oelhafen of the University of Basel for his seminal work in the field and the discussions with him on energy efficiency in trains. This work was financially supported by the Swiss Federal Office of Transport, Bern, Switzerland, with the BAV project No. 79. We are grateful for this support. The measurements of the fire properties were supported financially and with materials by the company va-Q-tec. We would like to thank Wim Malfait and three anonymous reviewers for their valuable comments on the first version of the manuscript. Finally, we are indebted to Joshua Yip for language corrections of the manuscript.

Conflicts of Interest: The authors declare no conflict of interest.

\section{References}

1. Chang, Y.; Lei, S.; Teng, J.; Zhang, J.; Zhang, L.; Xu, X. The energy use and environmental emissions of high-speed rail transportation in China: A bottom-up modeling. Energy 2019, 182, 1193-1201. [CrossRef]

2. Huang, Y.; Yang, L.; Tang, T.; Gao, Z.; Cao, F. Joint train scheduling optimization with service quality and energy efficiency in urban rail transit networks. Energy 2017, 138, 1124-1147. [CrossRef]

3. Zhang, H.; Jia, L.; Wang, L.; Xu, X. Energy consumption optimization of train operation for railway systems: Algorithm development and real-world case study. J. Clean. Prod. 2019, 214, 1024-1037. [CrossRef]

4. Feng, X.; Mao, B.; Feng, X.; Feng, J. Study on the maximum operation speeds of metro trains for energy saving as well as transport efficiency improvement. Energy 2011, 36, 6577-6582. [CrossRef]

5. Barone, G.; Buonomano, A.; Forzano, C.; Palombo, A. Enhancing trains envelope-—heating, ventilation, and air conditioning systems: A new dynamic simulation approach for energy, economic, environmental impact and thermal comfort analyses. Energy 2020, 204, 117833. [CrossRef]

6. Sidler, F. Simulation Energiebilanz Heizung Lüftung Klima: ICN (SBB) (Engl.: "Simulation Energy Balance Heating Ventilation Cooling: $\left.\operatorname{ICN}(S B B)^{\prime \prime}\right)$; BAV: Bern, Switzerland, 2018.

7. Hofstadter, R.N.; Amaya, J.; Kozek, M. Energy optimal control of thermal comfort in trams. Appl. Therm. Eng. 2018, 143, 812-821. [CrossRef]

8. Vetterli, N.; Menti, U.-P.; Sidler, F.; Thaler, E.; Zweifel, G. Energy efficiency of railway vehicles. In Proceedings of the International Conference CISBAT 2015 Future Buildings and Districts Sustainability from Nano to Urban Scale, Lausanne, Switzerland, 9-11 September 2015; pp. 955-960. [CrossRef]

9. Powell, J.P.; González-Gil, A.; Palacin, R. Experimental assessment of the energy consumption of urban rail vehicles during stabling hours: Influence of ambient temperature. Appl. Therm. Eng. 2014, 66, 541-547. [CrossRef]

10. Oelhafen, P.; Tonin, A. Energieeffizienz von Heizung, Lüftung und Kühlung im Öffentlichen Verkehr (Engl.: "Energy Efficiency of Heating, Ventilation and Cooling in Public Transport"); Bundesamt für Verkehr BAV: Bern, Switzerland, 2018.

11. Tuchschmid, M.; Wüst, P. Bibliothek Wärmedämmmaterialien (Engl.: "Database for Thermal Insulation Materials"); Schienenfahrzeugen, SBB AG: Bern, Switzerland, 2016.

12. Björk, F.; Enochsson, T. Properties of thermal insulation materials during extreme environment changes. Constr. Build. Mater. 2009, 23, 2189-2195. [CrossRef]

13. Isenschmid, C. Potentialanalyse für Verbesserung der Wärmedämmung bei der Fahrzeug-Aussenhülle-S-Bahn-Gliederzug BLS RABe 525 NINA (Engl.: "Analysis of Improvement Potential of the Thermal Insulation of the Vehicle Envelope-Suburban Train BLS RABe 525 NINA"); Bundesamt für Verkehr BAV: Bern, Switzerland, 2018.

14. Haller, G. Thermische Behaglichkeit in Schienenfahrzeugen (Engl.: “Thermal Comfort in Railway Vehicles"); Klima-Wind-Kanal Wien; RTA Rail Tec Arsenal Fahrzeugversuchsanlage GmbH: Vienna, Austria, 2006.

15. Lechtenböhmer, S.; Schüring, A. The potential for large-scale savings from insulating residential buildings in the EU. Energy Effic. 2011, 4, 257-270. [CrossRef]

16. Wohlgemuth, D.; von Gunten, D.; Manz, H.; Zeyer, C.; Althaus, H.-J. Ökologisch optimale Dämmdicken bei Wohngebäuden (Engl.: "Ecologically optimal insulation thicknesses for residential buildings"). Bauphysik 2015, 37, 277-283. [CrossRef]

17. Ganobjak, M.; Brunner, S.; Wernery, J. Aerogel materials for heritage buildings: Materials, properties and case studies. J. Cult. Herit. 2019. [CrossRef] 
18. Wernery, J.; Rigacci, A.; Achard, P.; Koebel, M.M. Aerogels for Superinsulation—Properties, Products and Applications. In Aerogel Handbook; Springer: Berlin/Heidelberg, Germany, 2021; in press.

19. Ugoo. Available online: http://en.ugootec.com/high_speed_railway (accessed on 29 August 2020).

20. Jinna. Available online: http://www.cnjinna.com/en_us/category/guidaokeche.html (accessed on 29 August 2020).

21. Gaedtke, M.; Wachter, S.; Kunkel, S.; Sonnick, S.; Rädle, M.; Nirschl, H.; Krause, M.J. Numerical study on the application of vacuum insulation panels and a latent heat storage for refrigerated vehicles with a large Eddy lattice Boltzmann method. Heat Mass Transf. 2020, 56, 1189-1201. [CrossRef]

22. Kraus, E.; Hack, U.; Baudrit, B.; Heidemeyer, P.; Bastian, M.; Wollheim, T.; Caps, R.; Wiegmann, W.; Fricke, M. Under high dynamic load. Adhes Adhes Sealants 2016, 13, 34-39. [CrossRef]

23. Automotive. Available online: https:/ /va-q-tec.com/automotive/ (accessed on 31 August 2020).

24. VIPs for Refrigeration Van. Available online: https://www.linkedin.com/posts/va-q-tec_insulation-logistics-endurancetestactivity-6698923671152594944-VJR8 (accessed on 31 August 2020).

25. DIN EN 13501-1:2019-05, Klassifizierung von Bauprodukten und Bauarten zu ihrem Brandverhalten_-Teil_1: Klassifizierung mit den Ergebnissen aus den Prüfungen zum Brandverhalten von Bauprodukten; Deutsche Fassung EN_13501-1:2018 (Engl.: "Fire Classification of Construction Products and Building Elements_Part 1: Classification Using Data from Reaction to Fire Tests; German Version EN 13501-1:2018"); Beuth Verlag GmbH: Berlin, Germany, 2019. [CrossRef]

26. Heinemann, U.; Adl-Zarrabi, B.; Brunner, S.; Foray, G.; Johansson, P.; Kono, J.; Kücükpinar, E.; Milow, B.; Quenard, D.; Sprengard, C.; et al. Annex 65 Long-Term Performance of Super-Insulating-Materials in Building Components and Systems. Report of Subtask I: State of the Art and Case Studies; Bavarian Centre for Applied Energy Research: Würzburg, Germany, 2020.

27. Kalnæs, S.E.; Jelle, B.P. Vacuum insulation panel products: A state-of-the-art review and future research pathways. Appl. Energy 2014, 116, 355-375. [CrossRef]

28. Baetens, R.; Jelle, B.P.; Gustavsen, A. Aerogel insulation for building applications: A state-of-the-art review. Energy Build. 2011, 43, 761-769. [CrossRef]

29. Günther, E.; Fricke, M.; Lölsberg, W.; Klinkebiel, A.; Weinrich, D. New Aerogel Products for Construction Use: Product Specifications, Application Examples, Practical Aspects. E3s Web Conf. 2020, 172, 21005. [CrossRef]

30. CALOSTAT®Product Information-Evonik Industries. Available online: https://www.calostat.com/en/product-information (accessed on 3 March 2021).

31. Stec, A.A.; Hull, T.R. Assessment of the fire toxicity of building insulation materials. Energy Build. 2011, 43, 498-506. [CrossRef]

32. Ghazi Wakili, K.; Stahl, T.; Brunner, S. Effective thermal conductivity of a staggered double layer of vacuum insulation panels. Energy Build. 2011, 43, 1241-1246. [CrossRef]

33. Stahl, T.; Brunner, S.; Zimmermann, M.; Wakili, K.G. Thermo-hygric properties of a newly developed aerogel based insulation rendering for both exterior and interior applications. Energy Build. 2012, 44, 114-117. [CrossRef]

34. Zhao, S.; Manic, M.S.; Ruiz-Gonzalez, F.; Koebel, M.M. Aerogels. In The Sol-Gel Handbook; Wiley-VCH: Weinheim, Germany, 2015; pp. 519-574. ISBN 978-3-527-67081-9.

35. EN 45545-2+A1 Railway Applications-Fire Protection on Railway Vehicles_Part 2: Requirements for Fire Behavior of Materials and Components; International Organization for Standardization: Geneva, Switzerland, 2016.

36. EN ISO 5659-2:2006 Plastics—Smoke Generation—Part 2: Determination of Optical Density by a Single-Chamber Test; International Organization for Standardization: Geneva, Switzerland, 2006.

37. EN ISO 5658-2:2006 Reaction to Fire Tests-Spread of Flame-Part 2: Lateral Spread on Building and Transport Products in Vertical Configuration; International Organization for Standardization: Geneva, Switzerland, 2006.

38. EN ISO 11925-2:2010 Reaction to Fire Tests-Ignitability of Products Subjected to Direct Impingement of Flame-Part 2: Single-Flame Source Test; International Organization for Standardization: Geneva, Switzerland, 2010.

39. EN ISO 5660-1:2015 Reaction-to-Fire Tests-Heat Release, Smoke Production and Mass Loss Rate-Part 1: Heat Release Rate (Cone Calorimeter Method) and Smoke Production Rate (Dynamic Measurement); International Organization for Standardization: Geneva, Switzerland, 2015.

40. IEC 61373 Railway Applications_Rolling Stock Equipment_Shock and Vibration Tests; International Organization for Standardization: Geneva, Switzerland, 2010.

41. Sia-Norm, Baustoffkennwerte (Engl.: "Norm of the Swiss Society of Engineers and Architects-Characteristical Values of Building Materials"), Sia I Schweizerischer Ingenieur-Und Architektenverein. 2020. Available online: https://www.sia.ch/de/ dienstleistungen/sia-norm/ (accessed on 7 October 2020).

42. IBU Veröffentlichte EPDs I Institut Bauen und Umwelt, e.V. Available online: https://ibu-epd.com/veroeffentlichte-epds/ (accessed on 5 March 2021).

43. EPD International S-P-00725—Spaceloft@Aerogel Insulation. Available online: https://www.environdec.com/library/epd725 (accessed on 5 March 2021).

44. Oekobaudat Prozess-Datensatz: Melaminharz-Schaum (de). 2018. Available online: https://www.oekobaudat.de/OEKOBAU. DAT/datasetdetail/process.xhtml?uuid=7082b2c3-5203-40ba-a6f8-d16edba60f5f\&lang=de (accessed on 5 March 2021).

45. Simmler, H.; Brunner, S. Vacuum insulation panels for building application: Basic properties, aging mechanisms and service life. Energy Build. 2005, 37, 1122-1131. [CrossRef] 
46. Heizgradtage (HGT)_HEV Schweiz. Available online: https://www.hev-schweiz.ch/vermieten/nebenkostenabrechnungen/ heizgradtage-hgt/ (accessed on 5 March 2021).

47. SPIEGEL, D. Deutsche Bahn Kauft 18 Neue ICE 4 (Engl.: “German Railway Company DB Buys 18 New ICE 4”). 2018. Available online: https: / www.spiegel.de/wirtschaft/ unternehmen/deutsche-bahn-kauft-18-neue-ice-4-a-1230331.html (accessed on 5 March 2021).

48. BAV Senkt in Absprache Mit SBB den Bahnstrompreis (Engl.: "Federal Office of Transport Reduces the Railway Electricity Price in Understanding with Swiss Federal Railways"). Available online: https://www.admin.ch/gov/de/start/dokumentation/ medienmitteilungen.msg-id-72867.html (accessed on 12 March 2021).

49. Renewable Energy Statistics—Statistics Explained. Available online: https:/ / ec.europa.eu/eurostat/statistics-explained/index. php/Renewable_energy_statistics\#Share_of_renewable_energy_more_than_doubled_between_2004_and_2019 (accessed on 12 March 2021).

50. BAV; SBB AG; BLS AG. Prüfung des Anreizes zur Steigerung der Energieeffizienz Durch das Trassenpreismodell; Eidgenössische Finanzkontrolle: Bern, Switzerland, 2017. 